\title{
HUBUNGAN ANTARA POWER OTOT LENGAN DAN BAHU, POWER OTOT TUNGKAI DAN KELENTUKAN PERGELANGAN TANGAN DENGAN DENGAN HASIL SMASH PADA VOLI TIM BOLA VOLI PENDOR UNIVERISTAS RIAU
}

\author{
Aref Vai.,S.Pd.,M.Pd, Drs. Ramadi,M.Kes AIFO, Boyke Johanes \\ aref.vai@lecturer.unri.ac.id
}

\section{ABSTRAK}

Tujuan penelitian ini untuk mengetahui apakah : Apakah terdapat hubungan antara power otot lengan dan bahu dengan ketepatan Smash Pada Tim Bola voli Pendor Univeristas Riau.? Apakah terdapat hubungan antara Power Otot Tungkai terhadap ketepatan Smash Pada Tim Bola voli Tim Bola voli Pendor Univeristas Riau Apakah terdapat hubungan antara kelentukan pergelangan tangan terhadap ketepatan Smash Pada Tim Bola voli Tim Bola voli Pendor Univeristas Riau.? Apakah terdapat hubungan antara power otot lengan dan bahu, power otot tungkai dan Kelentukan pergelangan tangan terhadap ketepatan Smash Pada Tim Bola voli Tim Bola voli Pendor Univeristas Riau.? Penelitian ini dilakukan dengan menggunakan penelitian kolerasional yang bertujuan untuk mengetahui seberapa jauh variabel-variabel pada suatu faktor yang berkaitan dengan faktor lain. Populasi penelitian adalah atlet Putra Tim bolavoli Pendor Universitas Riau sebanyak 16 orang. Teknik pengambilan sampel menggunakan teknik total sampling diperoleh 16 orang. Variabel penelitian meliputi variabel bebas terdiri dari daya ledak otot tungkai, kekuatan otot lengan, kelentukan pergelangan tangan dan variabel terikat adalah hasil Ketepatan smash. Hasil analisis data diperoleh perhitungan daya ledak otot tungkai, kekuatan otot lengan, kelentukan pergelangan tangan dengan hasil smash normal diketahui $\mathrm{F}_{\text {hitung }}$ masing-masing sebesar $18,02(\mathrm{X} 1), 34,56(\mathrm{X} 2)$, dan 21,88(X3) $>\mathrm{F}_{\text {tabel }} 4,60$ jadi hipotesis diterima. Artinya terdapat hubungan daya ledak otot tungkai, kekuatan otot lengan, dan kelentukan pergelangan tangan dengan hasil smash normal pada Tim bolavoli Pendor Universitas Riau.

Kata Kunci : Power Otot, Kelentukan, Bola Voli

\section{ABSTRACT}

The purpose of this study is to find out whether: Is there a relationship between the power of the arm and shoulder muscles with the accuracy of Smash on the Volleyball Team of the University of Riau Pendor? Is there a relationship between Leg Muscle Power to Smash Accuracy in Volleyball Team Volleyball Team University of Riau Pendor Is there a relationship between wrist flexion to Smash accuracy in Volleyball Team Volleyball Team of the University of Riau Pendor? Is there a relationship between the power of the arm and shoulder muscles, the muscle power of the limbs and the wrist flexion of the accuracy of the Smash on the Volleyball Team of the Volleyball Team of the University of Riau? This research was conducted using collegial research which aims to find out how far the variables on a factor are related to other factors. The study population was 16 male athletes from the volleyball team at the University of Riau. The sampling technique uses total sampling technique obtained by 16 people. The research variables included the independent variables consisting of explosive limb muscle strength, arm muscle strength, wrist flexibility and the dependent variable was the result of the accuracy of the smash. The results of data analysis obtained calculation of leg muscle explosive power, arm muscle strength, wrist flexion with normal smash results known Fcount of 18.02 (X1), 34.56 (X2), and 21.88 (X3) respectively> Ftable 4.60 so the hypothesis is accepted. This means that there is a relationship between leg muscle explosive power, arm muscle strength, and wrist flexibility with normal smash results on the Volleyball Team of the University of Riau. 


\section{PENDAHULUAN}

Olahraga merupakan aktivitas
fisik yang dilakukan untuk mendapatkan tubuh sehat dan kuat, aktivitas itu sendiri cenderung yang menyenangkan dan menghibur. Kata olahraga berasal dari bahasa Indonesia asli, tidak sama dengan sport. Olahraga berarti mengolah atau menyempurnakan jasmani atau fisik. Melihat dari tujuannya, olahraga dibagi menjadi tiga yaitu olahraga pendidikan, olahraga prestasi, dan olahraga rekreasi. Olahraga pendidikan dilaksanakan di sekolah, olahraga prestasi dilakukan di club-club olahraga melalui induk cabang olahraga, sedangkan olahraga rekreasi dilakukan hanya untuk mengisi waktu luang.

Pembangunan olahraga merupakan bagian dari peningkatan kualitas manusia yang ditujukan pada peningkatan kesehatan jasmani dan rohani seluruh masyarakat indonesia. Disamping itu juga dapat memupuk watak, kepribadian, disiplin, sportifitas, dan kemampuan daya pikir serta pengembangan keterampilan olahraga. Perkembangan olahraga yang semakin cepat menjadikan olahraga salah satu hal yang sangat penting untuk diperhatikan oleh semua kalangan khususnya pemerintah.

Dalam undang-undang sistem keolahragaan nasional No. 3 Tahun 2005 (2006:2) meyatakan bahwah, "pembinaan dan pengembangan keolahragaan nasional yang dapat menjamin pemerataan akses terhadap olahraga, peningkatan kesehatan dan kebugaran, peningkatan prestasi dan manajemen keolahragaan yang mampu menghadapi tantanganserta tuntutan perubahan kehidupan nasional dan global memerlukan sistim keolahragaan nasional.

Pada pasal (4), juga menyatakan bahwa keolahragaan nasional juga bertujuan memelihara dan meningkatkan kesehatan dan kebugaran, prestasi, kualitas manusia, menanamkan nilai moral dan ahlak mulia, sportifitas, disiplin, mempererat dan membina persatuan dan kesatuan bangsa, memperkukuh ketahanan sosial, serta mengangkat harkat, martabat dan kehormatan bangsa, Depdiknas (2006:3).

Dalam penjelasan yang tertuang dalam undanng-undang keolahragaan nasional No. 3 Tahun 2005 (2006:2) diatas, maka dapat disimpulkan bahwa pendidikan olahraga, jasmani dan kesehatan merupakan bagian dari integrasi dari pendidikan keseluruhan, karena tujuan untuk mengembangkan aspek kebugaran jasmani, keterampilan gerak, keterampilan berpikir kritis, penalaran, stabilitas emosional, keterampilan sosial, dan aspek pola hidup sehat dalam membentuk kepribadian manusia.

Salah satu tujuan pembangunan dan pengembangan olahraga di Indonesia adalah untuk meningkatkan pembinaan dan keterampilan olahraga, diantaranya adalah olahraga bola voli. Permainan bola voli adalah cabang olahraga yang sangat digemari dan menurut parah ahli saat ini bolavoli tercatat sebagai olahraga yang menempati yang menempati urutan kedua yang terkenal didunia dengan pemain mencapai lebih dari 140 juta orang. Sampai sekarang, organisasi induk olahraga ini, international volley ball federation (IVBF), beranggotakan 180 negara (nuril ahmadi, 2007:1). Demikian pula di indonesia, olahraga bolavoli merupakan salah satu diantara banyak cabang olahraga yang populer dimasyarakat, permainan bola voli di gemari oleh masyarakat dari berbagai tingkat usia, anak-anak, remaja dan dewasa baik pria maupun wanita. Hal ini terbukti bahwah olahraga bola voli banyak dimainkan di kampuangkampung, di kantor-kantor maupun di sekolah-sekolah. Permainan bola voli dapat digunakan sebagai sarana untuk mendidik, sebab dengan olahraga bolavoli dapat menbentuk pribadi yang sportif, jujur, kerjasama, bertanggung jawab. Semua itu merupakan nilainilai pendidikan yang dapat ditanamkan. Oleh karena itu olahraga permainan bola voli cocok diterapkan dalam lingkungan masyarakat dan lingkungan sekolah.

Menurut Nuril Ahmadi (2007: 20), Permainan bola voli adalah suatu yang kompleks yang tidak mudah dilakukan setiap orang, diperlukan pengetahuan tentang teknik dasar dan lanjutan untuk dapat bermain bola voli. Teknik dasartersebutmeliputi passing 
bawah, passing atas, servis bawah, servisatas, melakukan smash dan blok. Dari beberapa teknik dasar dalam bola voli, smash merupakan salah satu faktor untuk memperoleh kemenangan dalam pertandingan bola voli, hal ini dapat dilihat pada saat pertandingan. Dalam permaian bola voli yang terdiri dari 3 set (Three Winning Set) dengan system reli point. Jika dalam permainan tim memenangkan 3 set maka tim tersebut dinyatakan menang, dan jika terjadi persamaan set maka dilanjutkan dengan babak terakhir. Dalam pertandingan, banyak faktorfaktor yang menyebabkan keterampilan smash seorang pemain tidak efektif diantaranya banyak terjadi kesalahan-kesalahan. Hal ini terjadi akibat kondisi fisik yang menurun sehingga keterampilan teknik menurun sertatekanan dari lawan dan penonton.

Selain dari pada itu kondisi fisik sangat dibutuhkan seorang pemain bola voli. Kondisi fisik adalah suatu kesatuan utuh dari komponenkomponen yang tidak dapat dipisahkan begitu saja baik peningkatan maupun pemeliharaannya. Diantara beberapa kondisi fisik tersebut adalah :kekuatan (strenghth), daya tahan (endurance), daya otot(muscular power), kecepatan (speed), daya lentur (flexibelity), kelincahan (agility), koordinasi (coordination), keseimbangan (balance), ketepatan (accuracy) dan reaksi (reaction), Sajoto(1995:8-9). Dari beberapa komponen komponen tersebut sangat dibutuhkan oleh seorang pemain bola voli, bukan hanya dalam melakukan gerakan passing, servis dan block saja, akan tetapi dibutuhkan dalam melakukan smash. Karena dalam pelaksanaannya smash merupakan tehnik yang harus diutamakan dan smash adalah senjata yang ampuh dalam memenangkan setiap rally dan menghasilkan angka. Namun tentunya smash yang dimaksud harus dilakukan dengan baik dan sempurna, kuat, tajam dan terarah, oleh karena itu komponen-komponen diatas sangat dibutuhkan. Dari penjelasan tersebut dapat disimpulkan bahwa di dalam permainan bola voli, harus mempunyai teknik dasar dan kondisi fisik yang baik. Untuk bisa mendapatkan atau menguasai teknik keterampilan dasar bola voli salah satunya smash, atletharus berlatih secara benar dan kontinyu terhadap semua faktor yang menentukan atau mempengaruhi penguasaan keterampilan dasar bolavoli tersebut. Smash atau pukulan spike merupakan gerakan memukul bola dengan kuat dan keras serta jalannya bola cepat, tajam dan menukik serta sulit diterima lawan apabila pukulan itu dilakukan dengan cepat dan tepat (Aip syarifuddin.1997:58), pada teknik smash inilah letak seninya permainan bola voli dan teknik ini termasuk teknik serangan mematikan untuk mendapatkan poin. apabila pemain hendak memenangkan pertandingan maka mau tidak mau harus menguasai teknik smash. adapun yang harus di perlukan untuk melakukan smash, pertama harus memiliki kelincahan,kedua memiliki power atau daya ledak yang tinggi, ketiga memiliki Felling untuk menentukan ketepatan atau timing yang tepat kapan saat bola akan di pukul, keempat harus memiliki kekuatan pukulan untuk memukul bola yang sempurna (Sukirno, 2012:18).

Power merupakan perpaduan antara komponen kecepatan maksimum dan kekuatan maksimum (Bompa,1994:317). seorang olahragawan yang memeiliki power dengan baik maka dapat dipastikan ia memiliki kemampuan fisik yang optimal. untuk menghasilkan kedua komponen tersebut diperlukan latihan dengan waktu yang relatip cukup lama melalui latihan yang keras, power akan selalu berkaitan dengan explosive atau daya ledak (Sukirno,2012:148).

Menurut (ismaryati,2008:101) kelentukan merupakan kemampuan menggerakkan tubuh atau bagian seluas mungkin tanpa terjadi ketegangan sendi dan cedra otot, terdapat dua macam kelentukan, yaitu kelentukan dinamis dan kelentukan statis, kelentukan dinamis adalah kemampuan menggunakan persendian dan otot secara terus menerus dalam ruang gerak yang penuh dengan cepat, dan tanpa tahanan gerakan. kelentukan statis adalah kemampuan sendi untuk melakukan gerak dalam ruang yang besar. kelentukan dibutuhkan oleh banyak cabang olahraga, namun demikian terdapat perbedaan kebutuhan kelentukan untuk setiap penampilannya. Hal ini akan 
sangat mudah ditandai dengan tingkat fleksibelitas persendian seluruh tubuh, terutama otot-otot, serta ligamenligamen disekitar persendian. Maka hal tersebut dapat disimpulkan semakin tinggi kelentukan sendi pergelangan tangan maka sudut gerak dalam ayunan tangan juga semakin besar, sehingga tenaga yang dihasilkan juga semakin besar.

Setelah diadakan studi pengamatan dan observasi yang dilakukan penulis di lapangan, dan juga berdasarkan informasi dari pelatih dan para atlet, bahwa cabang olahraga bola voli Pada Tim Bola voli Pendor Univeristas Riau. sampai saat ini belum mampu menunjukkan prestasi yang maksimal. Salah satu penyebabnya hal tersebut adalah smash, dan tentu saja hal tersebut dapat mempengaruhi hasil permainan bola voli pada Tim Bola voli Pendor Univeristas Riau..Masih banyak pemain yang mengalami kegagalan pada waktu melakukan smash bola voli. Kegagalan yang sering terjadi pada saat melakukan smash seperti : bola nyangkut di net, bola bisa dikembalikan atau di blok oleh lawan, bola tidak tepat sasaran atau bola keluar lapangan permainan. Kelemahan smash ini diduga faktor penyebabnya Karena, kondisi fisik yang belum maksimal, antara lain : power otot lengan dan bahu, dan kelentukan pergelangan tangan sehingga sulit bagi atlet mengarahkan smashnya.

Berdasarkan dari beberapa kegagalan yang terjadi pada saat melakukan smash pada permainan bolavoli Pada Tim Bola voli Pendor Universitas Riau, diduga faktor penyebabnya adalah kondisi fisik pemain seperti power otot lengan dan bahu, kelentukan pergelangan tangan sehingga peneliti ingin mengangkat judul penelitian ini Hubungan Power Otot Lengan dan Bahu dan Kelentukan Pergelangan Tangan dengan Ketepatan Smash Pada Tim Bola voli Pendor Univeristas Riau.

\section{METODOLOG}

Penelitian ini dilakukan dengan menggunakan penelitian kolerasional yang bertujuan untuk mengetahui seberapa jauh variabel-variabel pada suatu faktor yang berkaitan dengan faktor lain. Korelasi adalah suatu penelitian yang dirancang untuk menentukan tingkat hubungan variabel-variabel yang berbeda dalam suatu populasi dan bertujuan untuk mengetahui seberapa besar hubungan antara variabel bebas dan variabel terikat, (Suharsimi Arikunto, 2006: 131). Variabel bebas dalam penelitian ini adalah: power otot lengan dan bahu $\left(\mathrm{X}_{1}\right)$, Power Otot Tungkai $\left(\mathrm{X}_{2}\right)$ Kelentukan Pergelangan Tangan $\left(\mathrm{X}_{3}\right)$,dan variabel terikat yaitu ketepatan smash bola voli (Y). Tempat penelitian ini dilaksanakan di lapangan bolavoli Pendor Universitas Riau Rumbai. Populasi dalam penelitian ini adalah mahasiswa yang Tim Bola voli Pendor Univeristas Riau yang berjumlah 16 orang. Teknik pengambilan sampel dalam penelitian ini adalah teknik total sampling dengan sampel penelitiannya 16 orang. Instrumen yang digunkan untuk mengukur daya ledak otot lengan danbahu menggunakan tes Two-Hand Medecine Ball Put. (Ismaryati, 2006: 64- 65). Tes dan pengukuran kelentukan pergelangan tangan dari Ismaryati (2008:109). Instrument tes vertical power jump. Tes spike/smash Tes yang digunakan yaitu Tes ketepatan smash (Nurhasan :2001:168). Analisis regresi yang digunakan dalam penelitian adalah analisis regresi tunggal dan regresi ganda.

\section{HASIL PENELITIAN}

\section{Power otot lengan dan bahu}

Pengukuran power otot lengan dan bahu dilakukan dengan tes TwoHand Medecine Ball Put terhadap 16 orang sampel dengan nilai tertinggi 5.40 dan nilia minimum 3.40 rata-rata (mean) 4.46, simpangan baku (standar deviasi) 0.57. Untuk lebih jelasnya lihat pada distribusi frekuensi di bawah ini:.

Tabel 2. Distribusi Frekuensi Variabel Power otot lengan dan bahu $\left(\mathrm{X}_{1}\right)$

\begin{tabular}{|c|c|c|}
\hline $\begin{array}{c}\text { Kelas } \\
\text { interval }\end{array}$ & $\begin{array}{c}\text { Frekue } \\
\text { nsi } \\
\text { absolut } \\
\text { e (Fa) }\end{array}$ & $\begin{array}{c}\text { Frekuen } \\
\text { si } \\
\text { relative } \\
\text { (Fr) }\end{array}$ \\
\hline $3.4-3.7$ & 1 & 6.25 \\
\hline $3.8-4.1$ & 2 & 12.5 \\
\hline $4.2-4.5$ & 7 & 43.75 \\
\hline $4.6-4.9$ & 3 & 18.75 \\
\hline
\end{tabular}




\begin{tabular}{|c|c|c|}
\hline $5.0-5.3$ & 3 & 18.75 \\
\hline & 16 & 100 \\
\hline
\end{tabular}

Berdasarkan pada tabel distribusi frekuensi di atas dari 16 sampel, 1 orang $(6.25 \%)$ memiliki hasil power otot lengan dan bahu dengan nilai 3.43.7, kemudian 2 orang $(12.5 \%)$ memiliki hasil power otot lengan dan bahu dengan nilai 3.8-4.1, selanjutnya 7 orang $(43.75 \%)$ memiliki hasil power otot lengan dan bahu dengan nilai 4.2 - 4.5, kemudian 3 orang $(18.75 \%)$ memiliki hasil power otot lengan dan bahu dengan nilai 4.6-4.9, 3 orang (18.75\%) memiliki hasil power otot lengan dan bahu dengan nilai 5.0-5.3, untuk lebih jelasnya dapat dilihat pada gambar di bawah ini:

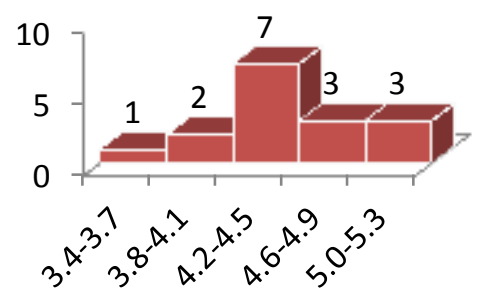

\section{Gambar 6. Histogram Power otot lengan dan bahu}

Power Otot Tungkai

Pengukuran power otot lengan dan bahu dilakukan dengan tes Vertical Jump terhadap 16 orang sampel dengan nilai tertinggi 63.00 dan nilia minimum 42.00 rata-rata (mean) 54.75, simpangan baku (standar deviasi) 5.71. Untuk lebih jelasnya lihat pada distribusi frekuensi di bawah ini:.

Tabel 2. Distribusi Frekuensi

Variabel Power Otot Tungkai $\left(\mathbf{X}_{2}\right)$

\begin{tabular}{|c|c|c|}
\hline $\begin{array}{c}\text { Kelas } \\
\text { interval }\end{array}$ & $\begin{array}{c}\text { Frekuensi } \\
\text { absolute } \\
\text { (Fa) }\end{array}$ & $\begin{array}{c}\text { Frekuensi } \\
\text { relative } \\
\text { (Fr) }\end{array}$ \\
\hline $42-45$ & 2 & 12.50 \\
\hline $46-49$ & 0 & 0 \\
\hline $50-53$ & 3 & 18.75 \\
\hline $54-57$ & 6 & 37.50 \\
\hline $58-61$ & 5 & 31.25 \\
\hline & 16 & 100 \\
\hline
\end{tabular}

Berdasarkan pada tabel distribusi frekuensi di atas dari 16 sampel, 2 orang $(12.50 \%)$ memiliki hasil power otot tungkai dengan nilai 42-45, kemudian 3 orang $(18.75 \%)$ memiliki hasil power otot tungkai dengan nilai $50-53$, selanjutnya 6 orang $(37.50 \%)$ memiliki hasil power otot tungkai dengan nilai 54-57, kemudian 5 orang
(31.25\%) memiliki hasil power otot tungkai dengan nilai 58-61, , untuk lebih jelasnya dapat dilihat pada gambar di bawah ini:

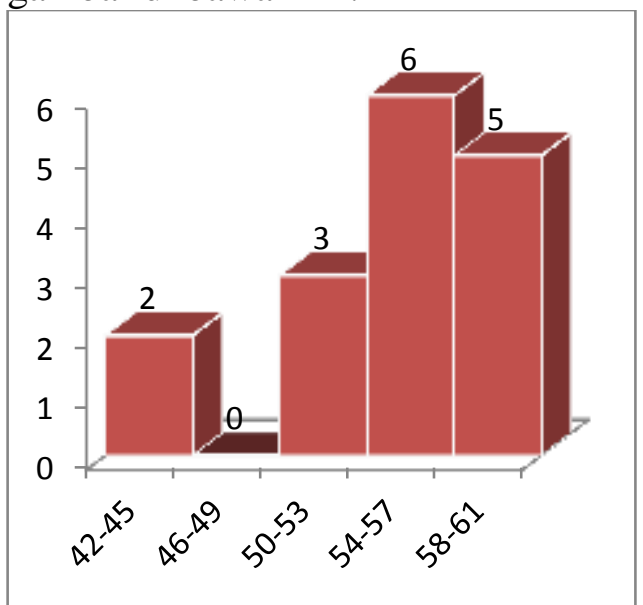
Gambar 6. Histogram Power
Otot Tungkai

\section{Kelentukan Pergelangan Tangan}

Pengukuran kelentukan pergelangan tangan dilakukan dengan tes kelentukan pergelangan tangan terhadap 16 orang sampel dengan nilai tertinggi 80 dan nilai minimum 50 rata-rata (mean) 65.19, simpangan baku (standar deviasi) 9.32. Untuk lebih jelasnya lihat pada distribusi frekuensi di bawah ini:.

Tabel 2. Distribusi Frekuensi

Variabel Kelentukan

Pergelangan Tangan $\left(\mathbf{X}_{\mathbf{3}}\right)$

\begin{tabular}{|c|c|c|}
\hline $\begin{array}{c}\text { Kelas } \\
\text { interv } \\
\text { al }\end{array}$ & $\begin{array}{c}\text { Frekuensi } \\
\text { absolute } \\
\text { (Fa) }\end{array}$ & $\begin{array}{c}\text { Frekuens } \\
\text { i relative } \\
\text { (Fr) }\end{array}$ \\
\hline $50-55$ & 4 & 25 \\
\hline $56-61$ & 0 & 0 \\
\hline $62-67$ & 4 & 25 \\
\hline $68-73$ & 4 & 25 \\
\hline $74-79$ & 4 & 25 \\
\hline & 16 & 100 \\
\hline
\end{tabular}

Berdasarkan pada tabel distribusi frekuensi di atas dari 16 sampel, 4 orang $(25 \%)$ memiliki hasil kelentukan pergelangan tangan dengan nilai 50-55 kemudian 4 orang $(25 \%)$ memiliki hasil kelentukan pergelangan tangan dengan nilai 62-67, selanjutnya 4 orang $(25 \%)$ memiliki hasil kelentukan pergelangan tangan dengan nilai $68-73$, kemudian 4 orang $(25 \%)$ memiliki hasil kelentukan pergelangan tangan dengan nilai 74-79. Untuk lebih jelasnya dapat dilihat pada gambar di bawah ini: 


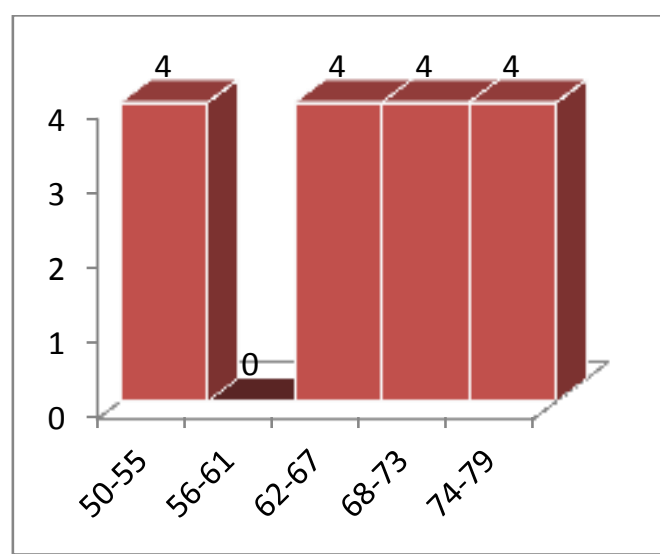

Gambar 6. Histogram Kelentukan Pergelangan tangan

Hasil Smash

Pengukuran Hasil smash normal dilakukan dengan tes smash dari laveage terhadap 16 orang sampel, didapat skor tertinggi 75, skor terendah 43, rata-rata (mean) 59.63, simpangan baku (standar deviasi) 8.16. Untuk lebih jelasnya dapat dilihat pada distribusi frekuensi di bawah ini:

Tabel 4. Distribusi Frekuensi Variabel Ketepatan smash

(Y)

\begin{tabular}{|c|c|c|}
\hline $\begin{array}{c}\text { Kelas } \\
\text { interval }\end{array}$ & $\begin{array}{l}\text { Frekuensi } \\
\text { absolute } \\
\text { (Fa) }\end{array}$ & $\begin{array}{l}\text { Frekuensi } \\
\text { relative } \\
\text { (Fr) }\end{array}$ \\
\hline $43-48$ & 1 & 6.25 \\
\hline $49-54$ & 3 & 18.75 \\
\hline $54-59$ & 3 & 18.75 \\
\hline $60-65$ & 5 & 31.25 \\
\hline \multirow[t]{2}{*}{$66-71$} & 4 & 25 \\
\hline & 16 & 100 \\
\hline
\end{tabular}

distribusi frekuensi di atas dari 16 sampel, 1 orang $(6.25 \%)$ memiliki hasil smash dengan rentangan nilai 4348, sedangkan 3 orang (18.75\%) memiliki hasil smash dengan rentangan nilai 49-54, kemudian 3 orang (18.75\%) memiliki hasil smash dengan rentangan nilai 54-59, selanjutnya 5 orang $(31.25 \%)$ memiliki hasil smash dengan rentangan nilai 6065 , dan 4 orang (25\%) memiliki hasil smash dengan rentangan nilai 66-71, untuk lebih jelasnya dapat dilihat pada gambar di bawah ini:

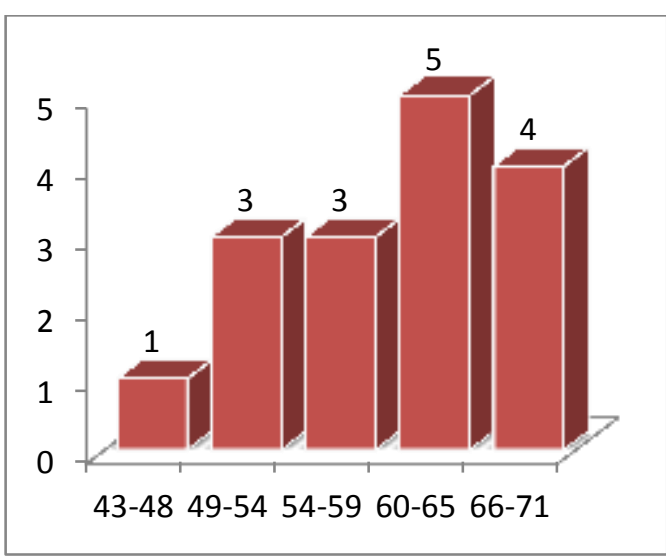

Gambar 8. Histogram Hasilsmash

\section{PEMBAHASAN}

Hubungan Power otot lengan dan bahu dengan Hasil Smash

Daya ledak atau explosive power adalah kemampuan seseorang untuk mempergunakan kekuatan maksimum yang dikerahkan dalam waktu yang sependek pendeknya, dalam hal ini dapat dinyatakan bahwa daya ledak adalah hasil dari perkalian antara kekuatan dengan kecepatan (Sajoto, 1995:8). Jadi untuk mendapatkan daya ledak yang bagus dan sempurna, maka seseorang itu harus melakukan berbagai latihan fisik yang berhubungan dengan daya ledak.

Otot adalah sebuah jaringan konektif yang tugas utamanya adalah berkontraksi yang berfungsi untuk menggerakkan bagian-bagian tubuh baik yang di sadari maupun yang tidak. Gerakkan tersebut di sebabkan karna kerja sama antara otot dan tulang.Tulang tidak dapat berfungsi sebagai alat gerak jika tidak di gerakkan oleh otot. Otot mampu menggerakkan tulang karna mempunyai kemampuan berkontraksi.

Perhitungan korelasi antara power otot lengan dan bahu $\left(\mathrm{X}_{1}\right)$ dengan ketepatan smash (Y) menggunakan rumus korelasi product moment. Kriteria pengujian jika $r_{\text {hitung }}$ $>\mathrm{r}_{\text {tabel }}$, maka terdapat hubungan yang signifikan dan sebaliknya (Sudjana 2002:369). Dari hasil perhitungan korelasi antara power otot lengan dan bahu dengan ketepatan smash diperoleh $F_{\text {hitung }} 18.01$ sedangkan $F_{\text {tabel }}$ pada taraf signifikan $\alpha=0.05$ yaitu 4.60. Berarti dalam terdapat hubungan antara power otot lengan dan bahu dengan hasil smash. 


\section{Hubungan Power otot tungkai dengan Hasil Smash}

Daya Daya ledak atau power sering juga disebut dengan eksplosif power atau muscular power. Power adalah hasil dari kekuatan dan kecepatan, Menurut Harsono (1988 : 200) bahwa "Power adalah kemampuan otot untuk mengarahkan kekuatan maksimal, dalam waktu yang sangat cepat".Kemudian menurut Sajoto (1995 : 8) bahwa daya ledak otot (Muscular power) adalah kemampuan seseorang untuk melakukan kekuatan maksimum, dengan usaha yang dikerahkan dalam waktu yang sependek-pendeknya". Sedangkan menurut Bompa (1999 : $61)$, power adalah kemampuan otot untuk mengeluarkan kekuatan maksimal dalam waktu yang amat singkat.

Perhitungan korelasi antara power otot lengan dan bahu $\left(\mathrm{X}_{2}\right)$ dengan ketepatan smash (Y) menggunakan rumus korelasi product moment. Kriteria pengujian jika $r_{\text {hitung }}$ $>r_{\text {tabel }}$, maka terdapat hubungan yang signifikan dan sebaliknya (Sudjana 2002:369). Dari hasil perhitungan korelasi antara power otot lengan dan bahu dengan ketepatan smash diperoleh $F_{\text {hitung }} 34.56$ sedangkan $F_{\text {tabel }}$ pada taraf signifikan $\alpha=0.05$ yaitu 4.60. Berarti dalam terdapat hubungan antara power otot lengan dan bahu dengan hasil smash.

\section{Kelentukan pergelangan tangan dengan hasil smash}

\section{Kelentukan} merupakan kemampuan tubuh untuk melakukan latihan-latihan dengan amplitudo gerakan yang besar dan luas. Dengan kata lain kelenturan merupakan kemampuan pergelangan/persendihan untuk melakukan gerakan-gerakan ke semua arah secara optimal.

Menurut Ismaryati (2008:101), kelentukan adalah kemampuan menggerakan tubuh atau bagianbagian seluas mungkin tanpa terjadi ketegangan sendi dan cedera otot. Sedangkan menurut M.Sajoto (1995:9) daya lentur adalah efektivitas seseorang dalam penyesuain diri untuk segala aktivitas dengan penguluran tubuh yang luas. Hal ini akan sangat mudah di tandai dengan tingkat fleksibilitas persendihan pada seluruh tubuh.
Dari penjelasan diatas penulis dapat menjelaskan bahwa kelentukan adalah kemampuan seseorang untuk dapat menggerakkan tubuh dalam satu gerakan dengan seluas-luas mungkin tanpa mengalami cedera sendi dan otot. Untuk itu kelentukan pergelangan tangan sangat dibutuhkan dan diperlukan dalam melakukan smash.

Perhitungan korelasi antara kelentukan pergelangan tangan $\left(\mathrm{X}_{3}\right)$ dengan ketepatan servis atas (Y) menggunakan rumus korelasi product moment. Kriteria pengujian jika $r_{\text {hitung }}$ $>\mathrm{r}_{\text {tabel }}$ Ho ditolak dan $\mathrm{Ha}$ diterima, maka terdapat hubungan yang signifikan dan sebaliknya (Sudjana 2002:369). Dari hasil perhitungan korelasi antara kelentukan pergelangan tangan dengan ketepatan servis atas diperoleh $F_{\text {hitung }} 21.88$ sedangkan $F_{\text {tabel }}$ pada taraf signifikan $\alpha=0.05$ yaitu 4.60. Berarti dalam hal ini terdapat hubungan antara kelentukan pergelangan tangan dengan hasil Smash.

Hubungan antara power otot lengan dan bahu, power otot tungkai dan kelentukan pergelangan tangan dengan hasil smash

Untuk mengetahui hubungan dari dua variabel atau lebih digunakan rumus Analisis Regresi ganda. Dari hasil perhitungan diperoleh analisis regresi ganda (uji $\mathrm{F}$ ) didapat $\mathrm{F}_{\text {hitung }}=$ 53.04 sedangkan $F_{\text {tabel }}$ diperoleh sebesar 4.60, jadi $F_{\text {hitung }}>F_{\text {tabel, }}$, artinya terdapat hubungan secara bersamasama antara power otot lengan dan bahu $\left(\mathrm{X}_{\mathrm{I}}\right)$, power otot tungkai $\left(\mathrm{X}_{2}\right)$ dan kelentukan pergelangan tangan $\left(\mathrm{X}_{3}\right)$ dengan kemampuan hasil smash (Y).

Berdasarkan uraian di atas jelas bahwa ketiga faktor tersebut dapat mempengaruhi hasil smash yang dilakukan seseorang dalam permainan bolavoli. Begitu juga sebaliknya masih banyak factor-faktor lain yang dapat mempengaruhi keterampilan dari seorang pemain bolavoli khususnya pada keterampilan smash normal.

\section{SIMPULAN DAN SARAN Kesimpulan}

a. Ada hubungan daya ledak otot tungkai dengan hasil smash pada Tim Bolavoli Pendor Universitas Riau dengan Fhitung 18,02 > $\mathrm{F}_{\text {tabel }} 4,60$ jadi hipotesis diterima 
b. Ada hubungan kekuatan otot lengan dengan hasil smash normal pada Tim Bolavoli Pendor Universitas Riau dengan Fhitung 34,56> $\mathrm{F}_{\text {tabel }} 4,60$ jadi hipotesis diterima

c. Ada hubungan kelentukan pergelangan tangan dengan hasil smash normal pada Tim Bolavoli Pendor Universitas Riau dengan Fhitung 21,88> $\mathrm{F}_{\text {tabel }}$ 4,60 jadi hipotesis diterima

d. Ada hubungan daya ledak otot tungkai, kekuatan otot lengan dan kelentukan pergelangan tangan dengan hasil smash normal pada Tim Bolavoli Pendor Universitas Riau dengan Fhitung 53,04

\section{Saran}

a. Bagi pelatih agar dapat meningkatkan keterampilan smash dengan penerapan bentuk latihan yang sesuai teknik dan sebagai materi penyusunan program latihan.

b. Bagi pemain bola voli agar memiliki ketepatan melakukan smash normal yang baik perlu berlatih teknik-teknik dasar smash seiring dengan peningkatan daya ledak otot tungkai, kekuatan otot lengan dan kelentukan pergelangan tangan secara seimbang.

c. Bagi peneliti lain yang berminat meneliti kembali permasalahan ini, hendaknya hasil penelitian ini sebagai bahan pertimbangan agar diperoleh

\section{DAFTAR PUSTAKA}

Arikunto, Shuarsimi.2006. Prosedur

Penelitian Suatau

Pendekatan Praktek.

Jakarta: PT Rineka Cipta.

Ismaryati.2008. Tes dan Pengukuran

Olahraga. Surakarta: LPP UNS dan UPT

Muhajir.2006. Pendidikan Jasmani Olahraga dan Kesehatan. Jakarta : Erlangga

Nurul Ahmadi.2007. Panduan Olahraga Bolavoli.

Surakarta : Pustaka umum
PBVSI.2004. Metodologi Pelatihan Bolavoli.Jakarta: ekretariat Umum PP.PBVSI

Nurhasan. 2001. Tes dan Pengukuran Depdikbud. Universitas Terbuka

Harsono. 2001. Latihan Kondisi Fisik. Jurusan Ilmu Keolahragaan Fakultas Ilmu Pendidikan Universitas Negeri Malang.

Sadoso.M. 1995. Peningkatan dan Pembinaan Kekuatan Kondisi Fisik dalan Olahraga. Semarang : Dahar Prize

1998. Pembinaan Kondisi Fisik dalam Olahraga. Jakarta. Dedpdikbud

Suharsono. H.P 1986. Ilmu Kepelatihan Olahraga. Yogyakarta: FPOK-IKIP Yogyakarta

1981. Metodik melatih Permainan Bola Voli. Yogyakarta: IKIP

Sukadiyanto. 2002. Teori dan Metodologi Melatih Fisik Tenis. Yogyakarta FIK UNY

Syafruddin. 1992. Pengantar Ilmu Melatih. Padang : UNP Press

Undang-Undang NO 3 Tahun 2005 Tentang Sistem Keolahragaan 